\title{
The Contingent Valuation Method: A Post-Kakadu Assessment
}

\author{
Jeff Bennett
}

7 The environmental dimension of public policy-making continues to grow in importance. Decisions as diverse as the relocation of the naval ammunition dump from Sydney and the drainage of saline sub-surface water in the Upper South-East of South Australia involve environmental issues that capture public interest. Economists charged with providing information to assist policy-makers in these cases are more and more being requested to deliver estimates of the values of environmental benefits and costs involved. This has proved difficult because the traditional valuation tools used by economists are based on data that are observable in markets. Most environmental benefits and costs, such as biodiversity conservation and air quality, are not bought and sold. New valuation techniques have had to be devised. For instance, where quantifiable relationships can be established between non-marketed environmental effects and marketed goods, economists have been able to infer the non-market values from available market data. People's preferences, as revealed by their behaviour in markets, are thus used to estimate their values for non-marketed environmental goods.

For some environmental effects, these revealed preference techniques are ineffective because of the absence of any related markets. This is usually the case for the so-called non-use values of the environment. These arise where people experience some gain or loss from the environment even though they do not come in direct contact with it. For example, people may gain satisfaction from the continued existence of an endangered species even though they have no desire to see it face to face. Similarly, people may suffer a loss when they hear that colonies of penguins have been harmed because of an oil spill. In such cases, values cannot be estimated through the analysis of peoples' revealed preferences. Reliance must be placed on the analysis of peoples' stated preferences. One such stated-preference valuation techniques is the Contingent Valuation Method (CVM).

\footnotetext{
The Travel Cost Method, for instance, establishes the value of the recreational experience by using people's revealed preferences for travelling to a recreational site. The Hedonic Pricing Technique uses the relationships existing between market prices (for real estate) and determining environmental factors (traffic noise, air quality) to estimate the value of those non-market factors. 2

The most comprehensive guide to CVM remains Mitchell and Carson (1989).
}

Jeff Bennett is Associate Professor in the School of Economics and Management, University College, The University of New South Wales, Canberra. 
The history of CVM in Australia is a rather chequered one. But a watershed in the use of the technique occurred in 1990 when the Resource Assessment Commission (RAC) released the results of its CVM analysis of the environmental costs likely to arise from proposed mining activities at Coronation Hill (Imber, Stevenson \& Wilks, 1990). This study became widely known as the 'Kakadu study' because the Coronation Hill site is adjacent to Kakadu National Park in the Northern Territory.

\section{The Elements of Contingent Valuation}

CVM involves asking a sample of people experiencing the non-market benefit or cost under consideration how willing they are to pay for a hypothetical project or program that will either provide the benefit or prevent the cost. ${ }^{3}$ The method is called 'contingent' because the estimates of value it yields are dependent on the construct of the 'market' that is formed in the questioning process.

No single template describes all CVM questionnaires. But most involve three elements. First, the hypothetical program or project that is being proposed is described. For example, a proposal to declare a new National Park may secure the continued survival of an endangered species; or a requirement for all oil tankers to be double-hulled may reduce the possibility of an oil spill. Second, a mechanism for eliciting the respondents' values is established. An 'open-ended' payment question would be of the fonn 'What is the most you would be prepared to pay in increased taxes for project X?'. Alternatively, a 'dichotomous choice' CVM question takes the form 'Would you be willing to pay $\$ \mathrm{X}$ in increased taxes for project $\mathrm{Z}$ ?', where the amount of $\$ \mathrm{X}$ is varied across a pre-determined range. Third, the socioeconomic and attitudinal characteristics of the respondent are sought for estimation and validation purposes.

\section{Background}

The origins of CVM can be traced back to Ciriacy-Wantrup (1947) in the US. In Australia, the method achieved a public profile only in 1990, with the release of the RAC's Kakadu study. Prior to that, CVM applications had been mostly small-scale and limited largely to academic studies. The New South Wales EPA Environmental Values Data Base lists twelve Australian CVM studies that pre-date the one at Kakadu. In these studies, which appear in data collected in 1979 (Bennett, 1984; Johnston, 1982; Scott; 1982), the method was applied in cases including air quality, protected areas, recreation, soil erosion and water quality. Although Australian economists lagged behind their US counterparts in applying CVM, they were among the vanguard of those experimenting with the technique in the rest of the world.

The breakthrough in the use of CVM in Australia occurred when the RAC commissioned a study of the environmental costs expected from a proposed mining

A willingness to accept compensation format is an altenative. 
venture at Coronation Hill. The study was undertaken with a view to providing value estimates to be incorporated into a benefit-cost analysis of a proposal to allow mining to proceed. It was the first CVM application in Australia that related to a high-profile, national policy issue.

The results of the study precipitated a lively debate. The estimate of the environmental costs of mining at Coronation Hill provided by the CVM application was in the order of 60 times greater than the estimate of the surplus generated by mining. Not surprisingly, the interests supporting the mining venture claimed that the CVM estimate was unrealistically high. They were backed by Brunton (1991), who suggested that respondents to the CVM questiomnaire had enjoyed a 'moral free lunch' by registering their opinions with 'play money'; furthermore, he argued that to compare the 'play money' values against the 'real money' generated by mining was fundamientally flawed. Moran (1991) argued that respondents to the Kakadu CVM questionnaire were not constrained by any real budget; nor were they fully appraised of the array of substitute goods that were available for the Coronation Hill site. He also suggested that most respondents were entirely unfamiliar with the area and were thus very poorly placed to value its environment. The media were particularly taken by Moran's comparison of the per hectare CVM value of the Coronation Hill site with land prices in downtown Tokyo. Moran estimated, on the basis of the values offered by the RAC study, that Coronation Hill, which had been described by one federal minister as 'clapped-out buffalo country', was the more valuable real estate.

The RAC did not allow the criticism to go unchallenged. Carson (1991), a leading American CVM researcher who had been appointed as an adviser to the RAC's CVM project team, attacked the critics' 'glib characterisations', which demonstrated 'a complete lack of understanding of welfare economics'. For instance, he argued that Moran's comparison of the price per hectare of Tokyo real estate with the consumer surplus per hectare estimate provided by the CVM study of the Coronation Hill environment was inappropriate, since two different economic concepts were being compared. Furthermore, it was a comparison between a private good, where the benefits can be captured by the individual who owns the property, and a public good, where individuals' benefits can be summed. Carson's rebuttal relied very strongly on the evidence, provided by US studies, that well designed and implemented CVM applications are capable of yielding accurate estimates across a wide variety of benefits and costs.

Whatever the validity of the Kakadu CVM estimates, the RAC's final report on the proposal to mine Coronation Hill made only passing reference to the study. It undertook no explicit benefit-cost analysis of the mining proposal, and included only a descriptive statement of the CVM work. But although the critics of CVM could view the $\mathrm{RAC}$ report a vindication of their efforts, their criticism was not ef-

\footnotetext{
'This has become known as the 'embedding eflect': when individuals are asked how much they are willing to pay for a good as a separate item, they are likely to bid more than when the question forms only one component of a sequence of willingness-to-pay questions.
} 
fective in ensuring the success of the mining proposal, since the federal government decided to incorporate the Coronation Hill site as an extension to Kakadu National Park. The decision was, however, based not on environmental factors but rather on the significance of the site to the aboriginal people of the area.

\section{The Exxon Valdez and the NOAA Panel}

While the debate over the validity of the Kakadu CVM study was taking place in Australia, a parallel debate was proceeding in the US. Following the grounding of the Exxon Valdez in Prince William Sound, Alaska, in 1989, the US federal government and the Alaskan State govenument launched legal suits against the Exxon Corporation for the recovery of damages caused to the natural resources affected by the resultant oil spill. Under the so-called 'Superfund' legislation, trustees were permitted to sue for loss of use and non-use values derived from natural resource damage. Furthermore, Department of the Interior regulations specified the CVM as an appropriate technique for estimating these values. With such high stakes involved, the CVM became the focus of attention, and valuation studies were commissioned by the Alaskan and federal governments and by Exxon.

CVM was also receiving attention from another quarter. After the Exxon Valdez spill, the US congress passed The Oil Pollution Act as a means of reducing the likelihood of future spills and recovering damages if a spill should occur. As part of that legislation, the Department of Commerce, acting through the National Oceanic and Atmospheric Administration (NOAA), was required to establish regulations pertaining to the estimation of damages. To perform the task of drawing up the required valuation regulations, NOAA set up a panel of experts, led by Nobel laureates Kenneth Arrow and Robert Solow, to assess the ability of the CVM to yield reliable estimates of natural resource damages. ${ }^{6}$ The panel concluded (Arrow et al., 1993) that ' $\mathrm{CV}$ studies can produce estimates reliable enough to be the starting point of a judicial process of damage assessment, including lost passive-use values'.

However, the decision in favour of the CVM was not unconditional. The panel was careful to state that CVM estimates were only one input into the process of determining damage assessments. It was also at pains to put the onus of proof of the appropriateness of CVM studies on those undertaking them. Perhaps most important, the panel set out numerous guidelines that it considered necessary to be followed for a CVM application to yield reliable results. These guidelines - in much condensed form - are:

\footnotetext{
${ }^{5}$ Use values relate to the benefits people receive from a direct involvement with the resource, such as recreational use. Non-use values are enjoyed by people who are removed from the resource; for example, the benefit received from knowing that an endangered species remains in existence is a non-use value.

6

The issues central to the US debate are set out in papers by Portney (1994), Hanemann (1994) and Diamond and Hausman (1994). Portney was a member of the NOAA panel, Hanemann was a consultant to the State of Alaska in the Exxon case, and Diamond and Hausman were employed by the Exxon Corporation.
} 
- Personal interviews should be used.

- Willingness to pay for projected events should be elicited.

- The dichotomous choice questioning form should be used.

- The hypothetical situation described should be accurate and understandable.

- Reminders regarding respondents' budget constraints should be included.

- Reminders of available substitute goods should be included.

- Follow-up questioning to ascertain the level of understanding achieved should be included.

It must be noted that the rigour required by these guidelines implies that applying the CVM for litigation purposes would be costly. Furthermore, the guidelines seem intended to generate conservative estimates. Nevertheless, it is apparent that the panel's deliberations have fortified the advocates of CVM. However, the out-of court settlement by Exxon for the natural resource damages caused by the Valdez spill amounted to only about one-third of the damages estimated by the trustees' CVM applications. It therefore remains to be determined how much weight the judicial process would give CVM estimates; but it would seem that the trustees in the Exxon case were confident of a proportion not greater than one-third.

\section{Post-Kakadu Applications}

In contrast to the US and Europe, only a very limited array of CVM applications has been performed in Australia in the 1990s. The debate arising from the Kakadu application has discouraged decision makers from commissioning further studies. Moreover, the scepticism that arose from the Kakadu study has been reinforced by some post-Kakadu applications. For instance, the Commission of Inquiry set up by the Queensland govenmment to investigate another high-profile resource use decision - the future of Fraser Island - received a submission from the Queensland Department of the Environment that included a CVM application. In this case, the value of the old-growth forests of the island was estimated. Like the Kakadu study, the Fraser Island analysis (Hundloe et al., 1990) yielded estimates that swamped the value of the extractive resource-use alternative. As with the Kakadu results, the Fraser Island values were not incorporated into the final report of the Commission, and the decision to stop logging on the island was made without reference to the CVM results.

The RAC undertook a further CVM application before its demise in 1994. That application, which formed part of the Forest and Timber Inquiry, was designed to estimate the value of protecting the old-growth forests in the south-east of Australia. The Final Report of the Inquiry noted the results of the study - which were of a more modest magnitude than either the Fraser Island or Kakadu estimates - but concluded that they were not sufficiently reliable to form the basis of policy decisions (Bennett \& Carter, 1994).

A further application of CVM occurred when the NSW Department of Water Resources used it in an experiment to estimate the value of water quality improvements in the Darling River (Hill, 1994). Currently, the Australian Bureau of Agri- 
cultural and Resource Economics is involved in a CVM application designed to estimate some environmental costs of increasing soil salinity levels in the Upper South Fast of South Australia. Other studies have been more academically oriented. Jakobsson (1994) used CVM to estimate the existence value of Leadbeter's Possum. Flatley and Bennett (1994) applied the technique in estimating the values placed by Australian tourists visiting Vanuatu on tropical forest protection. Blamey (1995) undertook extensive testing of the behavioural assumptions implied in the use of the CVM. But use of the technique has not exploded in Australia as it has elsewhere.

The NOAA panel's findings have had a very strong influence on the way in which CV studies have been undertaken, especially in the US. It appears that, in order to win legitimacy, studies must be matched against the NOAA guidelines. This is true not just for studies that are aimed at providing evidence for litigation, but also for applications designed to provide ball-park value estimates to natural resource decision-makers. The effect of this has been to make the CVM a more complex and more expensive instrument to implement. This is demonstrated by a CVM application performed by Carson et al. (1994) for NOAA as evidence for a Superfund litigation case. The application involved estimating the environmental costs caused by the release of DDT and PCBs into the Southern Californian Bight through the outfall pipes of the Los Angeles County sewer system. The study took over three years to complete. The development work included focus groups, $\operatorname{cog}$ nitive interviews, small pre-tests and pilot studies. The main survey consisted of 2,810 in-person interviews. The findings of the study are reported in a volume of 250 pages and are accompanied by an even thicker volume of appendices. At every stage, the study's development and performance is self-evaluated by comparison with the recommendations of the NOAA panel. In particular, extensive 'reliability' tests are performed. Primarily, these involve the assessment of relationships between respondents' valuation choices and various independent variables such as the cost of remedial works, the respondents' socio-economic characteristics, and their interest in, and proximity to, the damage. However, most stress is placed on the ability of the valuation data to demonstrate sensitivity to the scope of the environmental damage described to respondents in the CVM survey. That is, it was necessary to show that the CVM-generated value for extensive damage is significantly greater than a similarly determined estimate of lesser damage.

Clearly, the expense involved in undertaking a study of the magnitude of the Carson et al. (1994) work will rarely be justified in the Australian context. The value of the improved information provided by such a study has to be weighed

${ }^{7}$ Evidence of this explosion is provided in Carson et al. (1995), which lists 2,131 CVM studies and papers world-wide. The CVM Newsletter, coordinated from the Swedish University of Agricultural Sciences, is now distributed to 225 members worldwide.

${ }^{8}$ Carson et al. (1994) report a per household estimate of US\$55.61 for the damage. This extrapolates over the population of California to an aggregate estimate of US\$575m (with a standard error of $\$ 27 \mathrm{~m})$. 
against the additional costs of supplying it. As Flatley and Bennett (1994) point out, the future of CVM, particularly in developing country applications, will be determined by its ability to provide reliable information at an affordable cost. The direction taken by CVM applications in the US litigation setting is therefore questionable for a wide range of cases where non-market value information would be useful to decision makers. What then are the alternatives?

\section{Choice Modelling}

The NOAA panel findings are important in providing policy-makers using CVM results some guidance as to the quality of the estimates provided. However, the importance that has been placed on the findings of the NOAA panel, and the implied seal of approval it has given a particular version of CVM, may militate against the development of a wide diversity of methodological variations. Such diversity is important in the evolution of the technique. The greater the array of CVM variants being trialed, the greater will be the chance and rate of improvement.

The brake on the development of CVM this implies will most likely be applied hardest in the areas of litigation and policy advice. It can be expected that experimentation will continue among academic researchers. This trend is evident from recent work that has attempted to merge CVM with techniques developed in the disciplines of marketing and psychology. The resultant approach has become known as 'choice modelling' (Louvière, 1994). Iı a clioice modelling exercise, respondents are faced with a sequence of choices between two or more options. Each option is made up of a set of attributes which includes the non-marketed element under consideration and a cost factor. Varying the levels of attributes gives rise to the array of options that make up the choice set. For instance, in a study aimed at estimating the existence value of tropical rainforest reserves in Vanuatu, Rolfe and Bennett (1996) present respondents with a set of 16 choices. Each choice is between two alternative proposals to set aside areas of tropical rainforests. Each proposal is made up of a specific combination of pre-tested attributes such as rarity, size, location and cost. The choices made by respondents are analysed statistically to determine the impact of each attribute. In turn, the contribution made by each attribute to the utility of the respondent relative to the contribution made by money is estimated, thus quantifying the trade-off that respondents are willing to make between more of the non-marketed attributes and less money. This is the willingnessto-pay measure of value that is required by benefit-cost analysis.

Choice modelling can be viewed simply as a variant of the CVM. Whereas the dichotomous choice model of the CVM involves a single choice where only the non-market element and the cost attributes are varied across the options available, choice modelling embodies a wider array of factors that are variable. The dichotomous choice of CVM is therefore expanded and repeated under choice modelling. What then is gained by the deepening and widening process?

Choice modelling has at least five advantages over conventional CVM. First, it allows the valuation exercise to be framed adequately. With a CVM application, it is necessary to ensure that respondents are well aware of the range of substitute and 
complement goods that are available, so that the single valuation choice made is not taken in a vacuum. Usually, this involves respondents being given a statement of availability and a caution to ensure that they bear in mind the availability of other goods when making their choice. This is an adjunct to the questioning process and may not be well assimilated by respondents. Under the choice modelling approach, substitute and complement goods can be included as options or as attributes, and become integral to the choice process. The framing provided is therefore much stronger. In the Rolfe and Bemnett (1996) study, the Vanuatu rainforest reserves being valued are framed against an array of substitute areas in both Australia and overseas.

Second, under the choice modelling approach, cost is only one of a number of attributes that vary across a sequence of choices. This tends to downplay the significance of the dollar value trade-off in the choice exercise. The incentive for respondents to behave strategically could thus be smaller than under the CVM approach, where the dollar trade-off is made more explicit. Choice modelling also makes it possible to introduce a range of marketed and non-marketed goods as options. This can assist respondents in coming to terms with the concept of non-marketed goods being included in choices where money is involved.

Third, the variety of attributes and options that can be presented to respondents makes it possible to reduce the significance of any particular attribute or option that evokes significant protest. This situation may arise if specific ill-will is directed at a corporation or a govenument that is involved in the provision of a non-marketed effect that could impact on respondents' choices independent of their underlying valuations.

Fourth, the introduction of both marketed and non-marketed goods in a choice modelling exercise opens the way for the calibration of the non-market effect. It is also possible to integrate market data relating to ex post circumstances into choice modelling data to calibrate the data. For instance, Louvière (1994) demonstrates the integration of travel-cost method (revealed preference) into a set of choice modelling (stated preference) data to calibrate estimates of ski-field recreational values.

Finally, choice modelling allows the various contributing attributes of an option to be valued. It is therefore possible to create hypothetical scenarios of option combinations and carry out ex ante estimations of value. The technique presents an opportunity to introduce a new degree of flexibility into the value estimation process. It makes it possible to transfer valuations across a variety of case studies. For instance, a choice modelling exercise directed at valuing wetlands, generically, could provide data relevant to the valuation of a wide range of specific wetland sites.

Choice modelling thus appears to offer some advantages over conventional CVM as an estimation technique. But its development is still at a relatively early stage; and some doubts remain about its applicability. In particular, its ability to yield dollar valuations for non-market effects relies on a set of relatively restrictive assumptions. Substantial experimentation in developing the technique will be required for choice modelling to come of age. For instance, very little work has yet 
been done on the use of choice modelling to estimate non-use environmental values such as existence demand.

\section{Conclusions}

CVM has become widely used and accepted in the US and Europe as a technique for the estimation of non-market effects. Its acceptance in Australia has been far more limited and, as a consequence, it has been applied rather sparingly. This is despite particularly strong demands for estimates of non-market values being expressed by those responsible for resource use decisions where environmental consequences are apparent.

The high profile of the RAC's Kakadu study, the heated debate that followed it, and its eventual relegation from the policy-relevant category discredited it in the eyes of many Australian policy-makers. Subsequent domestic applications of the technique have done little to improve its local standing. For CVM to achieve in Australia the status it has attained overseas, policy-makers will need to become better informed about the technique itself. Like all tools of economic analysis, it has strengths and weaknesses. Its results need to be interpreted carefully. Above all, users of CVM results need to be aware of the differences between good and poor applications of the techmique. As has been demonstrated by the NOAA panel, many elements of a CVM study may be used to judge its reliability as a source of policy relevant information. Perhaps the single most important point for policymakers to realise is that the CVM will never provide simple answers for all natural resource allocation problems. All it can do is provide another element of information to the decision-making process. Over time, the quality of the information provided by CVM and its descendants, such as choice modelling, will be improved, but it will never be a panacea.

\section{References}

Arrow, K., R. Solow, P. Portuey, E. Leamer, R. Raduer \& H. Schuman (1993), 'Report of the NOAA Panel on Contingent Valuation', Federal Register 58: 4601-14.

Bennett, J. (1984), 'Using Direct Questioning to Value the Existence of a Preserved Natural Ecosystem', Australian Jounual of Agricultural Economics 28: 136-52.

_ \&. Carter (1993), 'Prospects for Contingent Valuation: Lessons from the South-East Forests', Australian Journal of Agricultural Economics 37: 79-93.

Blamey, R. (1995), Citizens, Consumers and Contingent Valuation: An Investigation into Respondent Behaviour, unpublished PhD thesis, Australian National University.

Brunton, R. (1991), Will Play Money Drive Out the Real Money, Institute of Public Affairs, Canberra (Environmental Backgrounder No. 2).

Carson, R. (1991), 'The RAC Kakadu Conservation Zone Contingent Valuation Study: Remarks on the Brunton, Stone and Tasman Institute Critiques', in Resource Assessment Commission (1991), Commentaries on the RAC's Contingent Valuation Survey of the Kakadu Conservation Zone, Canberra. 
Carson, R., M. Hanemann, R. Kopp, J. Krosnik, R. Mitchell, S. Presser, P. Rudd \& K. Smith (1994), Prospective Interim Lost Use Value due to DDT and PCB Contamination in the Southern Caljformiay Bight, Natural Resource Damage Assessment Inc., La Jolla.

Carson, R., J. Wright, N. Carson, A. Alberini \& N. Flores (199.5), A Bibliography of Contingent Valuation Studies and Papers, Natural Resource Damage Assessment Inc., La Jolla.

Ciriacy-Wantrup, S. (1947), 'Capital Returns from Soil-Conservation Practices', Journal of Farm Economics 29: 1181-96.

Diamond, P. \& J. Hausman (1994), 'Contingent Valuation: Is Some Number Better Than No Number', Jounal of Economic Perspectives 8(4): 4.5-64.

Flatley, G. \& J. Bennett (1994), The Value of Vanuatu Forest Protection to Australian Tourists, Department of Economics and Management, University College, The University of New South Wales, Canberra (Vanuatu Forest Conservation Research Report No. 6).

Hanemann, M. (1994), 'Valuing the Euvironment through Contingent Valuation', Journal of Economic Perspectives 8(4): 19-44.

Hill, C. (1994), 'Water Quality Improvement in the Darling River: a Contingent Valuation Surdy', paper presented to the 38th Conference of the Australian Agricultural Economics Society, Wellington.

Hundloe, T., G. McDonald, R. Blamey \& M. Carter (1990), Socioeconomic Analysis of NouExtractive Natural Resource Uses in the Great Sandy Region, Instiute of Applied Environmental Research, Griffith University.

Imber, D., G. Stevenson \& L. Wilks (1990), A Contingent Valuation Survey of the Kakadu Conservation Zone, Resource Assessment Commission, Canberra (Research Paper No. 3).

Jakobsson, K. (1994) Methodological Issues in Contingent Valuation: An Application to Endangered Species, unpublished PhD thesis, La Trobe University, Melbourne.

Johnston, B. (1982), 'External Benefits in Rural Research and the Question of Who Should Pay', paper presented to the 26th Annual Conference of the Australian Agricultural Economics Society, University of Melbourne, February.

Louvière, J. (1994), 'Relating Stated Preference Measures and Models to Choices in Real Markets: Calibration of CV Responses', paper presented for the DOE/EPA Workshop on Using Contingent Valuation to Measures Non-market Values, Hendon, Virginia, May 19-20.

Mitchell, R. \& R. Carson (1989), Using Surveys to Value Public Goods: The Contingent Valuation Method, The Johns Hopkins University Press, Washington DC.

Moran, A. (1991), Valuing the Kakadu Conservation Zone, Tasman Institute, Melbourne (Occasional Paper No. 138).

Portney, P. (1994), 'The Contingent Valuation Delate: Why Economists Should Care', Jounjal of Economic Perspectives 8(4): 3-18.

Rolfe, J. \& J. Bennett (1996), The Existence Demand for Vanuatu Forest-Protected Areas, Department of Economics and Management, University College, The University of New South Wales, Canberra (Vanuatu Forest Conservation Research Report No. 12).

Scott, W. (1982), Public Willingness to Pay for Clean Air, AGPS, Canberra (Australian Environment Council Report No. 7).

An earlier version of this article was delivered to a meeting of the Victorian Branch of the Australian Agricultural Economics Society in September 1995. 